\title{
Research and Implementation of 3D Mall System Based on DVR
}

\author{
Lifang Yang \\ Department of Computer Application, Chongqing College of Electronic Engineering , Chongqing, \\ 401331, China
}

Keywords: 3D mall; DVR; Interactive

\begin{abstract}
D Shopping site can only provide people with simple pictures and text messages without interaction and sense of reality. This paper argues how to solve these problems through 3D mall for it will become the future development trend of online shopping. In DVR(distributed virtual reality system) virtual environment virtual environment, the different position of multiple users can interact with the collaborative operation. From three perspectives of building a 3D model, designing an interaction function and creating a website, this paper puts forward a scheme of construction for 3D mall system under the environment of DVR By studying a necessity of the 3D mall。
\end{abstract}

According to a report which is issued in 2014 Q1 by IT research center of China, we can easily find out that online users have more than 310 million people and online shopping markets scale reaches up to 456.44 billion yuan. It is increased $27.6 \%$ than a year ago as shown in figure 1 . Obviously, shopping on line has become a new way of consumption 。

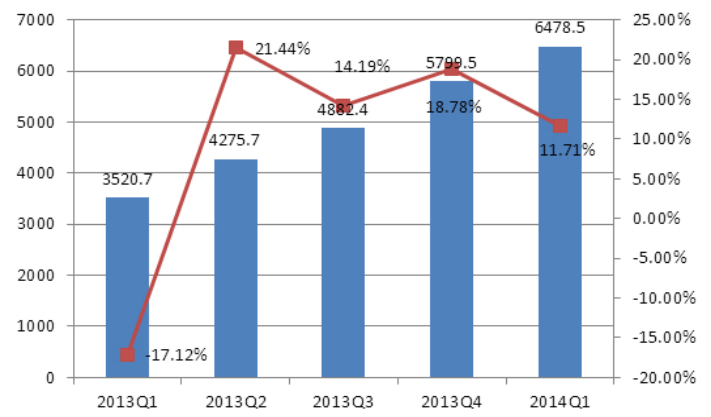

Figure 1. China's online Shopping Trends

Making more money from more users than before in a whole network, every online business how to show a strength, highlight an advantage of product, attract and obtain more new users have been being a most urgent tasks with the popularity of online shopping.

Now the display method of product through text and images is only based on 2D plane in the most of E-commerce sites, which not only makes online users be difficult to compare and choose their goods needed among the thousands of homogeneous website like a drop in the ocean, but also makes consumers dazzling.

\section{1、Advantages and disadvantages of $2 \mathrm{D}$ shopping website}

2D shopping website is based on 2D image display. It is convenient to browse, search and maintain, meanwhile, network transmission speed is fast and its cost is low. In the 2D shopping website, messages of commodities are described by texts and images, but the information passed to users is limited. So online users cannot be accurately to grasp these commodity information and these products can't experience directly under the virtual environment without authenticity and interactivity in the real world. However, in the traditional shopping consumers can do it with friends and bargain with merchants. Moreover, consumers can enjoy all kinds of decoration for physical stores during offline shopping. If tired, consumers can go to drink a cup of tea, see a movie for recreation. Compared to offline shopping, two-dimensional network shopping only can see pictures and words without feeling of the space scale and grade decoration of store. Therefore, we can conclude that $2 \mathrm{D}$ shopping is more convenient, but it reduces the enjoyment of shopping for consumers. 


\section{2、3D mall based on DVR}

(1) Summary of DVR (distributed virtual reality)

Distributed virtual reality system is referred to as "DVR, is a type of virtual reality system, it is based on the network virtual environment, in this environment, multiple users or more virtual environment locating in different position of the physical environment connected through the network, or multiple users to participate in a virtual reality environment at the same time, through the computer to interact with other users, and to share information. In the system, multiple users can through the network to observe and operate the same virtual world, in order to achieve the purpose of the collaborative work. In short, it refers to a software system, supporting the real-time interaction through a network, in a virtual reality environment, through the computer, each user interact with other users and share the information.

(2) The 3D mall

3D mall is a production of virtual reality technology and the network technology of rich media. $3 \mathrm{D}$ mall is the 3D rendering of the mall in real life on online, the mall in real life scenes, specifications and the mall management form, through the computer 3D technology, network technology, online payment and other technical means to build virtual shopping center in the network. in the mall, the shop is $3 \mathrm{D}$, the display of goods, including the appearance of the goods at any Angle to browse, users can roam in the 3D virtual environment, chat to interactive, the comprehensive virtual shopping to browse, choose, payment process, users have immersive feeling, beyond the existing network business platform, it has realized the unprecedented e-commerce "man-machine integration" and immersive 3D effect, to make up the unreality of 2D mall, increases the interest.

The 3D mall Based on DVR, is a virtual mall with a lot of people, it can let the customers go shopping with my friends, choose goods, try it on, bargain and waiters, to buy. Can chat with friends, discuss, and new friends to say hello, like a real shopping.

\section{3、Designing a scheme of 3D mall system}

3D mall have a variety of advantage that the 2D mall can't match, but 2D website can't be replaced for the convenience of use and SEO, at the same time the customer in 3D mall can't face goods directly and will spend much more time than in 2D store. Owning to limitation of the network bandwidth, users' satisfaction about network speed of shopping in the 3D mall is worse than 2D mall smooth. Considering consumption favor, building a mall of 2D and 3D, it not only gives full play to the characteristics of various systems and advantages, but also makes up for the inadequacy of 3D or 2D. The system scheme is shown in figure 2.

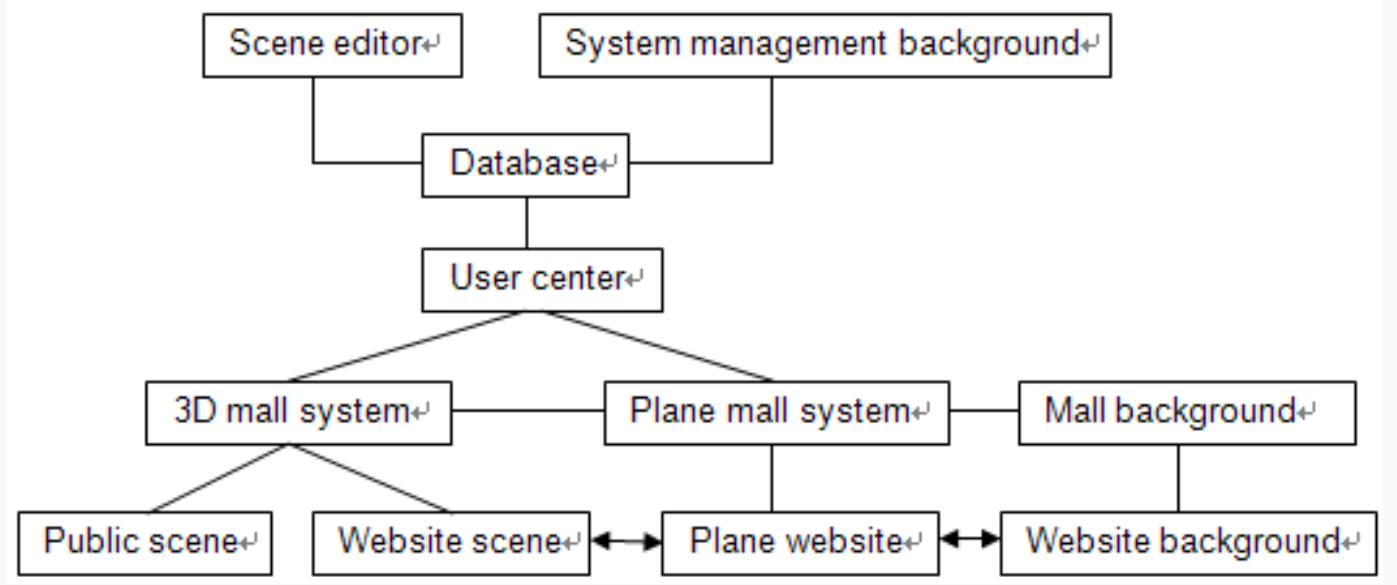

Figure2 3D Mall System Scheme

3D mall make 3D virtual reality technology and the two-dimensional information online system fuses in together, with the method of embedded IE page, 3D scene data in the browse process of 
customers, adopt dynamic multi-threading technology to download gradually to the local, not affecting the user action.

Through the open platform of 3D online mall, the businessman can easily show their latest technology and products via the Internet, easily realize real-time communication, demos, online trial and online transactions, and other functions in virtual showrooms. Its system structure is shown in figure 3.

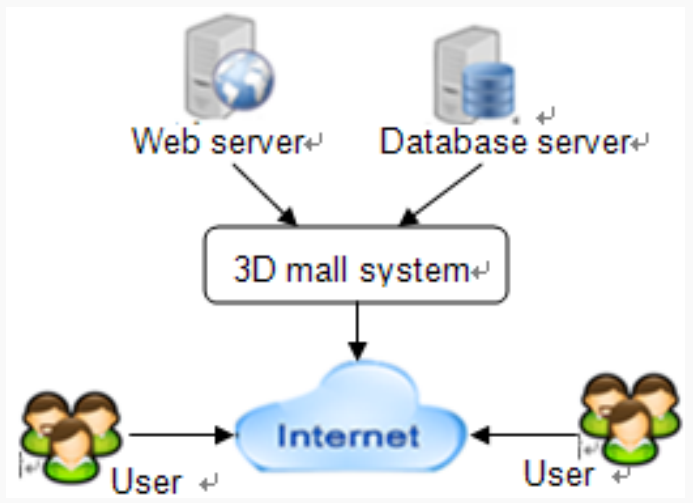

Figure3 3D mall system structure

\section{4、Building up a 3D mall}

(1) Building up a 3D model

Appearance models of malls, stores and goods are created using 3D software. 3D character should be created by the software. There are many types of modeling software using for tools VR system such as 3ds Max, Maya, Creator, and so on. As shown in figure 4, this paper uses the Creator to build up the 3D model.
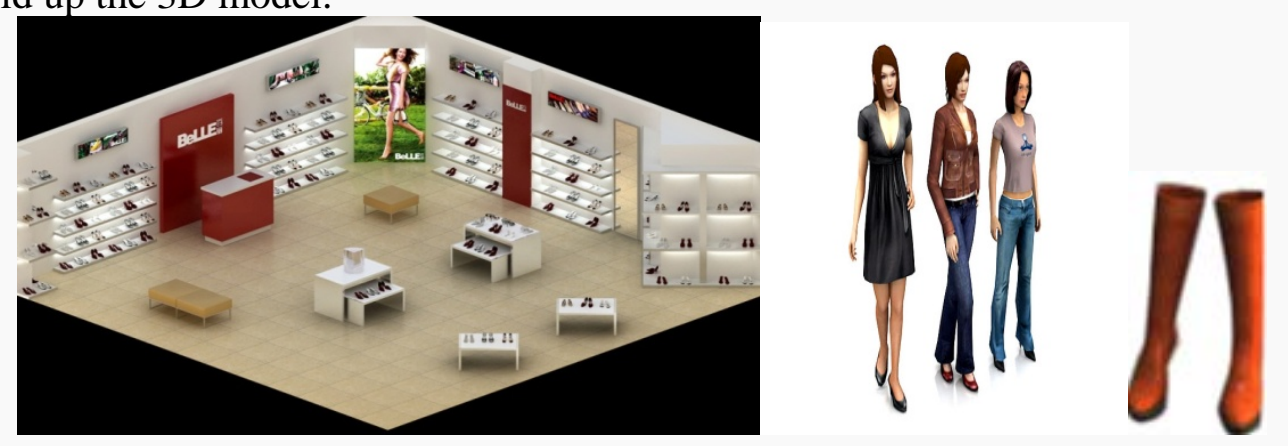

Figure4 3D model

(2) Designing an interaction function

The completed 3D model is imported into the virtual reality software to realize interactive design. VRML, Java3D, Cult3D and Virtools are common virtual reality software. The paper uses Virtools to design the interact function, as shown in figure 5 and 6. Through interaction design, user can conveniently realize the interactive control of the product, roaming in the mall, collision detection. In constructing a virtual world, users can get most true feelings. The final output is a web format file. 


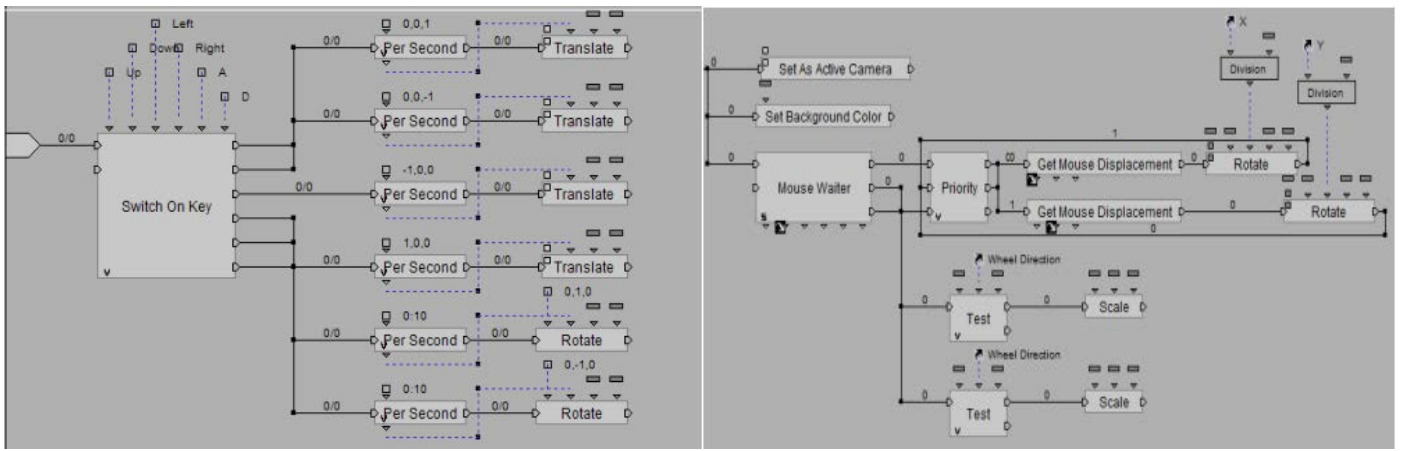

Figure 5 Roaming procedure programming

Figure 6 Product interactive programming

(3) Creating an website

In order to realize the online purchase function, dynamic websites, the database, relational database are created by using Asp.net. To achieve interactive operation functions in web, the three-dimensional virtual shopping made completely is embed into the mall website.

<object id="Virtools" classid="CLSID:D4323BF2-006A-4440-A2F5-27E3E7AB25F8"

codebase="http://a532.g.akamai.net/f/532/5624/5m/virtools.download.akamai.com/5624/playe r/install/installer.exe\#Version=4,0,0,26"

height="640" width="640">

$<$ param name="SRC" value="Virtual shop.vmo" />

<embed height="300" name="Virtools" pluginspage="http://player.virtools.com/"

src=" Virtual shop.vmo" type="application/x-virtools" width="640" $></$ embed $>$

$</$ embed $>$

$</$ object $>$

\section{Acknowledgement}

The paper is one of the achievement of the Chongqing education science "twelfth five-year" plan project " E-commerce consulting personalized training mode study based on smile curve" (number: 2012 - GX - 189).

\section{References}

[1] Xiaofeng Li, Virtual Reality Technology in the field of E-Commerce Applications, Science \&Technology Vision[J], 2013 (23) 311-312.

[2] Jingjing Xu, Study on Prototype System of digital Mall Based on VR Technology[D], WanFang Data, December, 2012.

[3]ZhangJuan, Virtual Reality Technology in the Application of the Virtual Mall[J], Reform \& Openning[J], 2010 (11) 126-127.

[4]Zhangxuan, Virtul Scene Construction and Interactive Technology Research Based on E-commerce[D], CNKI,August,2008.

[5]Changbo, Distributed Virtual Reality System Research and Design[D], CNKI, June,2004. 